\title{
When Do Anticipated Guilt Ads Lead to Ethical Consumption? Identifying Moderating Variables from a Literature Review
}

\author{
Sabrina Spence, Kai-Yu Wang, Narongsak Thongpapanl, and Todd Green
}

\begin{abstract}
Recent research in the marketing literature indicates that while consumers' interest in ethical products is growing, demand for such products still remains weak. Previous research indicates that anticipated guilt can be an antecedent to ethical consumption. Thus, the objective of this chapter is to identify three possible moderating variables: socially responsible consumer behavior (SRCB), consumer attachment style, and perceived similarity that may impact the link between anticipated guilt and ethical consumption. Further, we discuss the possible underlying mechanisms of these effects. By identifying the role that these potential moderators play in the relationship between anticipated guilt and ethical consumption, this research provides propositions that future researchers can test with empirical studies in order to close research gaps and assist marketers in understanding when an anticipated guilt ad is an appropriate strategy in marketing ethical products.
\end{abstract}

S. Spence $(\bowtie) \bullet$ K.-Y. Wang $\bullet$ N. Thongpapanl $\bullet$ T. Green

Brock University, Saint Catharines, ON, Canada

e-mail: ss13kg@brocku.ca; kwang@brocku.ca;

nthongpa@brocku.ca; tgreen@brocku.ca 